\title{
Management of Paper-Thin Skin Tears Using a Silver-Based Hydrofiber Dressing
}

Honda Hsu

Dalin Tzu Chi Hospital

Ya-Hui Yen

Taichung Tzu Chi Hospital

Ya-Ting Tseng

Dalin Tzu Chi Hospital

Shu-Ping Chou

Dalin Tzu Chi Hospital

Chiou-Ping Chen

Dalin Tzu Chi Hospital

Hsin-Hua Ke

Dalin Tzu Chi Hospital

Yi-Kung Lee

Dalin Tzu Chi Hospital

Yung Cheng Su ( $\square$ drsu119@gmail.com )

Dalin Tzu Chi Hospital, Buddhist Tzu Chi Medical Foundation https://orcid.org/0000-0002-8201-1592

\section{Research Article}

Keywords: hydrofiber, ionic silver, skin tears, dressings

Posted Date: February 17th, 2022

DOI: https://doi.org/10.21203/rs.3.rs-919257/v1

License: (a) (i) This work is licensed under a Creative Commons Attribution 4.0 International License.

Read Full License 


\section{Abstract}

\section{Background}

Skin tear is a common problem encountered in the Emergency Department. If it is not properly managed, it can lead to wound infection, skin necrosis and a need for further surgical intervention and skin grafting. Current management is to cleanse the wound, replace the thin skin flap followed by coverage with a dressing that is inducive for wound healing. Several dressings have been suggested for the coverage of these wounds. But, up to now, there has been no mention of the use of a silver-based hydrofiber dressing in the management of this condition. The objective of this study was to explore the use of a silver-based hydrofiber dressing for the management of paper-thin skin tears.

\section{Methods}

We retrospectively reviewed all patients with class I or II skin tears that had undergone management using a silver based hydrofiber dressing between October 2019 till October 2020. Demographic data and medical history was obtained by retrospective chart review. Data that was collected included: age, sex, comorbid illnesses, defect location, defect size, complications, number of times the silver-based hydrofiber dressing was replaced and the number of days required to achieve complete wound healing.

\section{Results}

A total of 65 patients were included in the study. There were 39 males and 26 females. There were 28 patients whose age was greater then 85 years old, of which 14 patients were over 90 years old. The mean number of outpatient visits were 2 . The mean defect size was $33 \mathrm{~cm}^{2}$ (range $1 \mathrm{~cm} \times 1 \mathrm{~cm}$ to $\left.18 \times 10 \mathrm{~cm}\right)$. The mean number of days required for total wound healing was 13 days (range 7-21). We did not encounter any patients that required further surgical debridement or split-thickness skin grafting.

\section{Conclusion}

The use of a silver-based hydrofiber dressing was well tolerated by the elderly population as it provided an easy, efficient, economical and effective form of management of skin tears. We suggest that a silverbased hydrofiber dressing can be used as a first-line treatment method for class I and II skin tears.

\section{Background}

Skin tear is a common problem encountered in the Emergency Department, but are often not high on the list of priorities of management by the Emergency Room staff due to more serious life and death situations faced every day. However, if not properly managed, it can lead to wound infection, skin necrosis and a need for further surgical intervention and skin grafting. It is a problem that affects patients across all age spectrums but is especially prevalent in the elderly and in the chronically ill individuals. In the elderly population, minor traumas such as wheelchair or chair injuries, transferring from bed to chair, minor falls, bumps, and even tape removal can result in skin tears. Malone et al ${ }^{1}$ estimated that there are 
approximately 1.5 million skin tears annually in nursing homes in the United States. Others estimate that the prevalence of skin tears in the nursing homes range between $14-24 \%^{2}$.

The current recommended management is for a complete assessment of the wound to determine the type of skin tear. The wound should be thoroughly cleaned. Wound healing would only take place once surface debris, necrotic tissue, biofilms and foreign body had been removed. The thin skin flap should be replaced, realigned and if possible re-approximated ${ }^{3}$. Hydrogel, alginate, lipido-colloid based mesh and foam dressings, soft silicone, foam, calcium alginate dressings, absorbent clear acrylic dressings, and skin glue has all been described as dressings that can be used for the coverage of these wounds ${ }^{4,5}$.

But up to now, there has been no mention of using a silver-based hydrofiber dressing (Aquacel $\mathrm{Ag}^{\circledR}$, Convatec, London, UK) in the management of this common condition. The objective of this study was to explore the use of a silver-based hydrofiber dressing for the management of paper-thin skin tears. We assessed the time required to achieve complete wound healing as well as whether additional wound treatment therapies were required.

\section{Methods}

We conducted a single-center, retrospective, noncomparative study to evaluate the efficacy of using a silver-based hydrofiber dressing in the management of skin tears. All patients that had presented to the Emergency Department with class I or II skin tear and those that had undergone skin tear management using a silver based hydrofiber dressing, between October 2019 till October 2020, were included in the study. According to Payne and Martin's classification of skin tears, class I skin tears were defined as skin tears without any tissue loss, class II skin tears were defined as tears associated with partial tissue loss, and class III tears were defined as tears associated with complete tissue loss. ${ }^{6}$ Patients with deep, infected, heavily contaminated, and actively bleeding wounds that did not respond to application of local pressure were excluded. Avulsed full thickness flaps containing subcutaneous tissue were also excluded.

If skin tear management was performed with any other method they were excluded from the study. Demographic data that was collected included: age, sex, comorbid illnesses, defect location, defect size, complications, number of times the silver-based hydrofiber dressing was replaced and the number of days required to achieve complete wound healing. (Table 1). The study protocol was approved by the institution review board of our hospital and the requirement for a signed informed consent was waived due to the retrospective nature of the study.

\section{Interventions}

After patient stabilization, all wounds were cleansed with normal saline and bleeding was stopped with the application of direct local pressure. In patients with class I and II skin tears, the avulsed skin were placed back, realigned and their edges were re-approximated as much as possible. In some cases, surgical adhesive tape (Steri-Strips; 3M, St. Paul, MN) was used to assist in fixation after realignment. At 
times, complete re-approximation was not possible and remanent raw surfaces could be seen (Fig 1). The silver-based hydrofiber dressing was placed over the re-approximated skin as well as over the raw surface. Gauze was placed over this dressing and compression bandage was applied to ensure that the hydrofiber comes into direct contact with the skin tear and the raw surface. Sutures and staples were not used in any of these patients. The patients and their family were educated to remove the gauze dressing the following day and to review the silver-based hydrofiber dressing. If it was nice and dry, new gauze was placed over this. They were to do this on a daily basis. The patients were followed up 3 days later in the outpatient clinic (Fig 2). Repeat assessment of the dressing was made by the physician in the outpatient clinic and if it was nice and dry, the patient and their family was encouraged to carry on with daily changes of the gauze dressing. A follow up appointment was made for 1 week later, at which time the silver-based hydrofiber dressing was removed and the percentage of wound healing was determined. If the silver-based hydrofiber dressing was still firmly attached then removal was not undertaken and a further appointment was made for another week later. The need for silver-based hydrofiber dressing was stopped only when complete wound healing was seen (Fig 3). There was a variation in the timing of the removal of the silver-based hydrofiber dressing as this had to be adjusted to the days that the patients could return to the outpatient department for follow-up. In all of these patients, no further procedures were required. If the silver-based hydrofiber dressing looked saturated, it was removed and replaced with a new silver-based hydrofiber dressing. If there was infection of the wound with frank pus, the silver-based hydrofiber dressing was removed and was changed to Povidone-lodine coated dressing (Meidine ${ }^{\circledR}$, JenSheng, Taiwan), which was applied daily. The patient was placed on an oral antibiotic at this time.

\section{Results}

A total of 73 patients had undergone management of their skin tears using a silver-based hydrofiber dressing but 8 patients were lost to follow up. A final of 65 patients were included in the study. There were 39 males and 26 females. Their mean age was 83 years old. Interestingly, there were 28 patients in the study whose age was greater then 85 years old, of which 14 patients were over 90 years old. There were 28 patients whose skin tears were located in the arms, forearms and hands, 25 patient whose skin tears were located in the thighs, pretibial are and over the dorsal feet. In 5 patients the skin tear was over a mixed area of both the upper and lower extremity, in 2 patients the skin tears were over the face, and there was 1 patient where the skin tear was located over the anterior chest. There were no patients that were admitted either initially or during follow up for the skin tear injuries and no further surgical interventions were required. The mean number of days required for total wound healing was 13 days (range 7-21). The mean number of outpatient visits were 2. This did not include the visit to the Emergency Department. There were 3 patients who developed an infection of the wound. In these patients, the silver-based hydrofiber dressing was removed and changed to a Povidone-lodine coated gauze dressing. They were educated to change the dressing on a daily basis and were placed on oral antibiotics. Daily wound care was performed until the wound healed by secondary intention. In these 3 patients, they took an average of 24 days until complete wound healing. We were lucky not to encounter any patients that required 
further surgical debridement and split-thickness skin grafting. The mean defect size in these patients was $33 \mathrm{~cm}^{2}$ (range $1 \mathrm{~cm} \times 1 \mathrm{~cm}$ to $18 \times 10 \mathrm{~cm}$ ) (Table 1). Two illustrative cases are shown in Figs. 4a-d and 5a-c

The limitations of this study, was that this study was carried out in a single-center and was a retrospective, non-comparative study. There were also 8 patients that were loss to follow up. It is feasible, that they had presented to another hospital with wound infections.

\section{Discussion}

Skin tears were defined by Payne and Martin as "a traumatic injury occurring on the extremities of older adults as a result of shearing or friction forces, which separate the epidermis from the dermis." ${ }^{7}$ This was later revised in 1993 as, "a traumatic injury occurring principally on the extremities of older adults as a result of shearing or friction forces which separate the epidermis from the dermis (partial-thickness wound) or which separate both the epidermis and the dermis from the underlying structures (fullthickness wound)." ${ }^{6}$ This revised definition was later adapted as part of the Skin Tear Audit Research (STAR) skin tear classification system ${ }^{8}$. But regardless of the definition, skin tears occur commonly in the extremes of age, in the critically ill or medically compromised, and in those requiring assistance with daily activities. At present, the dressings commonly used for the management of skin tears include hydrogel, alginate, lipido-colloid based mesh and foam dressings, soft silicone, foam, calcium alginate dressings, absorbent clear acrylic dressings, and skin glue ${ }^{4,5}$. But there has been no description of the use of a hydrofiber dressing or a silver-based hydrofiber dressing for the management of this commonly seen problem.

This retrospective, noncomparative study showed that the use of a silver-based hydrofiber dressing in the management of class I and II skin tears in the Emergency Department setting, functions well, and is well accepted by the elderly and the general population. The application was easy and painless. The daily care of the dressing and the wound was stress-free and extremely well tolerated by the family members looking after the patient or even by the patient themselves. Out of all the patients, there were only 3 that had failed due to infection. The patients in this study were all extremely elderly, with an average age of 83 years old. There were 28 patients that were older than 85 years old and 14 patients that were over 90 years old. In the extremes of ages, you need to make wound care easy and fuss free. One has to take into account that in the elderly patient, there can be the presence of degenerative osteoarthritis or rheumatoid arthritis of the hands, leading to deterioration of fine motor skills. They are more susceptible to failing eyesight, as well as failing memory. Often, they might be living alone or in some circumstances it is one elderly family member looking after the other (elderly wife looking after elderly husband or vice versa). If the care of the wound becomes complicated, it will not be well tolerated by this group of patients. In this method, all the patients had to do at home was to change to gauze covering the silver-based hydrofiber dressing and to not get the dressing wet.

Silver has been used widely in wound management for many years to help control local infection. Historically, silver can be dispensed as metallic (silver foil), solution (eg, silver nitrate), or cream (eg, silver 
sulfadiazine). lonic silver ( $\mathrm{Ag}+)$ has received renewed interest as a prophylactic antimicrobial agent in wound dressings due to its broad spectrum antibacterial range. There are various mechanisms that can be used to explain the antimicrobial effect of ionic silver. Silver interferes with the cytochromes of microbacteria and additionally also interferes with components of the microbial electron transport system, binds DNA, and inhibits DNA replication. There is at present little evidence of emerging microbial resistance to silver. $^{9-13}$

Aquacel ${ }^{\circledR}$ Hydrofiber dressing (ConvaTec, London, UK) is a moisture- retention dressing. It consists of a soft non-woven sodium carboxymethylcellulose fibers. This becomes gel-like when it comes in contact with wound fluid. This gel promotes a moist wound-healing environment while at the same time it retains wound exudates by vertical absorption. Fibrin that collects between the hydrofiber and the wound surface acts as an adhesive, fixing the dressing in place, allowing the adherence of the dressing to the wound. ${ }^{14-}$ 20

It is based on these 2 properties that we used a silver-based hydrofiber for fixation of the paper-thin skin tears. Hydrofiber dressing has been applied to many types of wound care with favorable results and costeffectiveness. ${ }^{14-20}$ Silver-based hydrofiber has been used to treat partial thickness burns both in the adults and in the pediatric population. It has been used in chronic wounds, non-ischemic diabetic foot ulcers, split thickness skin graft donor sites and in acute traumatic wounds ${ }^{21-27}$. This is the first description of using it in the management of skin tears.

A further benefit of this method, was that it avoided the need for sutures or staples. Even though sutures and staples are not advised in these types of wounds, some patients still mistakenly undergo primary repair. By using this dressing, it avoids the risk for needle stick injuries, and decreases the treatment time required for the management of these types of injuries. This is very important in the Emergency Department where time is always in short supply. This method was also welcomed by the patients themselves, as they do not need to experience the pain associated with the injection of local anesthetics and suturing. The method was so simple, that after complete healing of the wound, some of the patients asked to purchase extra silver-based hydrofiber dressings to keep at home in case further injuries like these happens in future.

\section{Conclusion}

This study showed that the use of a silver-based hydrofiber dressing was well tolerated by the elderly population as it provided an easy, efficient, economical and effective form of management of skin tears. We suggest that a silver-based hydrofiber dressing can be used as a first-line treatment method for class I and II skin tears.

\section{Abbreviations}

$\mathrm{cm}=$ centimeter 
STAR = Skin Tear Audit Research

DNA = deoxyribonucleic acid

\section{Declarations}

\section{Ethics approval and consent to participate}

The study protocol was approved by the institution review board of Dalin Tzu Chi Hospital and the requirement for a signed informed consent was waived due to the retrospective nature of the study.

\section{Consent for publication}

Consent has been achieved for the publication of the photos and data.

\section{Availability of data and material}

The datasets generated during and/or analysed during the current study are available from the corresponding author on reasonable request.

\section{Competing interests}

The authors declare that they have no competing interests.

\section{Funding}

This study received no external funding or support and the silver-based hydrofiber dressing (Aquacel® $\mathrm{Ag}$ ) dressing was obtained through the normal hospital purchasing system.

\section{Author's contributions}

$\mathrm{HH}$ - conception and design, analysis, interpretation of data, initial and final draft of the manuscript and final approval of study

YHY-conception and design, analysis and interpretation of data, initial draft and final approval of study YTT - conception, acquisition of data and interpretation of data, final approval of study SPC - conception, acquisition of data and interpretation of data, final approval of study CPC - conception, acquisition of data and interpretation of data, final approval of study HHK - conception, acquisition of data and interpretation of data, final approval of study YKL - conception and design of study, interpretation of data, revision of draft, final approval of study 
YCS - conception and design, analysis, interpretation of data, initial and final draft of the manuscript and final approval of study

Acknowledgements : Not applicable

\section{References}

1. Malone M, Rozario N, Gavinski M, Goodwin J. The epidemiology of skin tears in the institutionalized elderly. JAGS. 1991;39:591-5.

2. Bank D, Nix D. Preventing skin tears in a nursing and rehabilitation center: an interdisciplinary effort. Ostomy Wound Manag. 2006;52(9):38-40.

3. Sibbald G, Orstead H, Coutts P, Keast D. Best practice recommendations for preparing the wound bed: update 2006. Wound Care Canada. 2006;4(1):19-29.

4. LeBlanc K, Baranoski S. Skin tears: state of the science: consensus statements for the prevention, prediction, assessment, and treatment of skin tears. Advances in skin wound care. 2011;24(9):1-15.

5. Xu X, Lau K, Taira BR, Singer AJ. The current management of skin tears. The American Journal of Emergency Medicine. 2009;27:729-33.

6. Payne RL, Martin ML. Defining and classifying skin tears: need for a common language. Ostomy Wound Manage. 1993;39:16-20.

7. Payne RL, Martin ML. The epidemiology and management of skin tears in older adults. Ostomy Wound Manage. 1990;26:26-37.

8. Carville K, Lewin G, Newall N, Haslehurst P, Micchael R, Santamaria N, et al. STAR: a consensus for skin tear classification. Prim Intent. 2007;15:18-28.

9. Burd A, Kwok CH, Hung SC, Chan HS, Gu H, Lam WK, et al. A comparative study of the cyto- toxicity of silver-based dressings in monolayer cell, tissue explant, and animal models. Wound Repair Regen. 2007;15(1):94-104.

10. Lansdown AB. Silver. Its antibacterial properties and mechanism of action. J Wound Care. 2002;(4):125-30. 11(.

11. Lansdown AB. Silver. 2: Toxicity in mammals and how its products aid wound repair. J Wound Care. 2002;11(5):173-7.

12. Mooney EK, Lippitt C, Friedman J. Silver dressings. Plast Reconstr Surg. 2006;117(2):666-9.

13. Poon VK, Burd A. In vitro cytotoxity of silver: implication for clinical wound care. Burns. 2004;30(2):140-7.

14. Barnea Y, Amir A, Leshem D, Zaretski A, Weiss J, Shaifi R, et al. Clinical comparative study of aquacel and paraffin gauze dressing for split-skin donor site treatment. Ann Plast Surg. 2004;53(2):132-6.

15. Chaby G, Senet P, Vaneau M, Martel P, Guillaume JC, Meaume S, et al. Dressings for acute and chronic wounds: a systematic review. Arch Dermatol. 2007;143(10):1297-304. 
16. Cohn SM, Lopez PP, Brown M, Namlas N, Jackowski J, Li P, et al. Open surgical wounds: how does Aquacel compare with wet-to-dry gauze? J Wound Care. 2004;13(1):10-2.

17. Guest JF, Ruiz FJ. Modelling the cost implications of using carboxy- methylcellulose dressing compared with gauze in the management of surgical wounds healing by secondary intention in the US and UK. Curr Med Res Opin. 2005;21(2):281-90.

18. Robinson BJ. The use of a hydrofibre dressing in wound management. J Wound Care. 2000;9(1):324.

19. TachiM HirabayashiS, SuzukiY YoneharaY. BowlerP. Comparison of bacteria-retaining ability of absorbent wound dressings. Int Wound J. 2004;1(3):177-81.

20. Williams C. An investigation of the benefits of Aquacel Hydrofibre wound dressing. Br J Nurs. 1999;8(10):676-80.

21. Caruso DM, Foster KN, Blome-Eberwein SA, Twomey JA, Herndon D, Luterman A, et al. Randomized clinical study of Hydrofiber dressing with silver or silver sulfadiazine in the management of partialthickness burns. J Burn Care Res. 2006;27(3):298-309.

22. Coutts P, Sibbald RG. The effect of a silver-containing Hydrofiber dressing on superficial wound bed and bacterial balance of chronic wounds. Int Wound J. 2005;2(4):348-56.

23. Jude EB, Apelqvist J, Spraul M, Martini J. Prospective randomized controlled study of Hydrofiber dressing containing ionic silver or cal- cium alginate dressings in non-ischaemic diabetic foot ulcers. Diabet Med. 2007;24(3):280-8.

24. Jurczak F, Dugre T, Johnstone A, Offori T, Vujovic Z, Hollander D. Randomised clinical trial of Hydrofiber dressing with silver versus povidone-iodine gauze in the management of open surgical and trau-matic wounds. Int Wound J. 2007;4(1):66-76.

25. Kazmierski M, Mankowski P, Jankowski A, Harasymczuk J. Comparison of the results of operative and conservative treatment of deep dermal partial-thickness scalds in children. Eur J Pediatr Surg. 2007;17(5):354-61.

26. Lohana P, Potokar TS. Aquacel Ag in paediatric burns: a prospective audit. Ann Burns Fire Disasters. 2006;19(3):1-10.

27. Mishra A, Whitaker IS, Potokar TS, Dickson WA. The use of Aquacel Ag in the treatment of partial thickness burns: a national study. Burns. 2007;33(5):679-80.

\section{Tables}

Table 1 : Summary of Patient Demographics and Results 
Total no of Patients

Male

Female

Mean Age (in years)

Location of Skin Tears

Upper Extremity

Lower Extremity

Mixed Areas

Face

Chest

Mean Defect Size $\left(\mathrm{cm}^{2}\right)$

No of Days till Total Wound Healing

Wound Infection (No of Patients)
65

39

26

83

28

25

5

2

1

33 (Range 1- 180)

13 (Range 7-21)

3

No $=$ number

Figures 


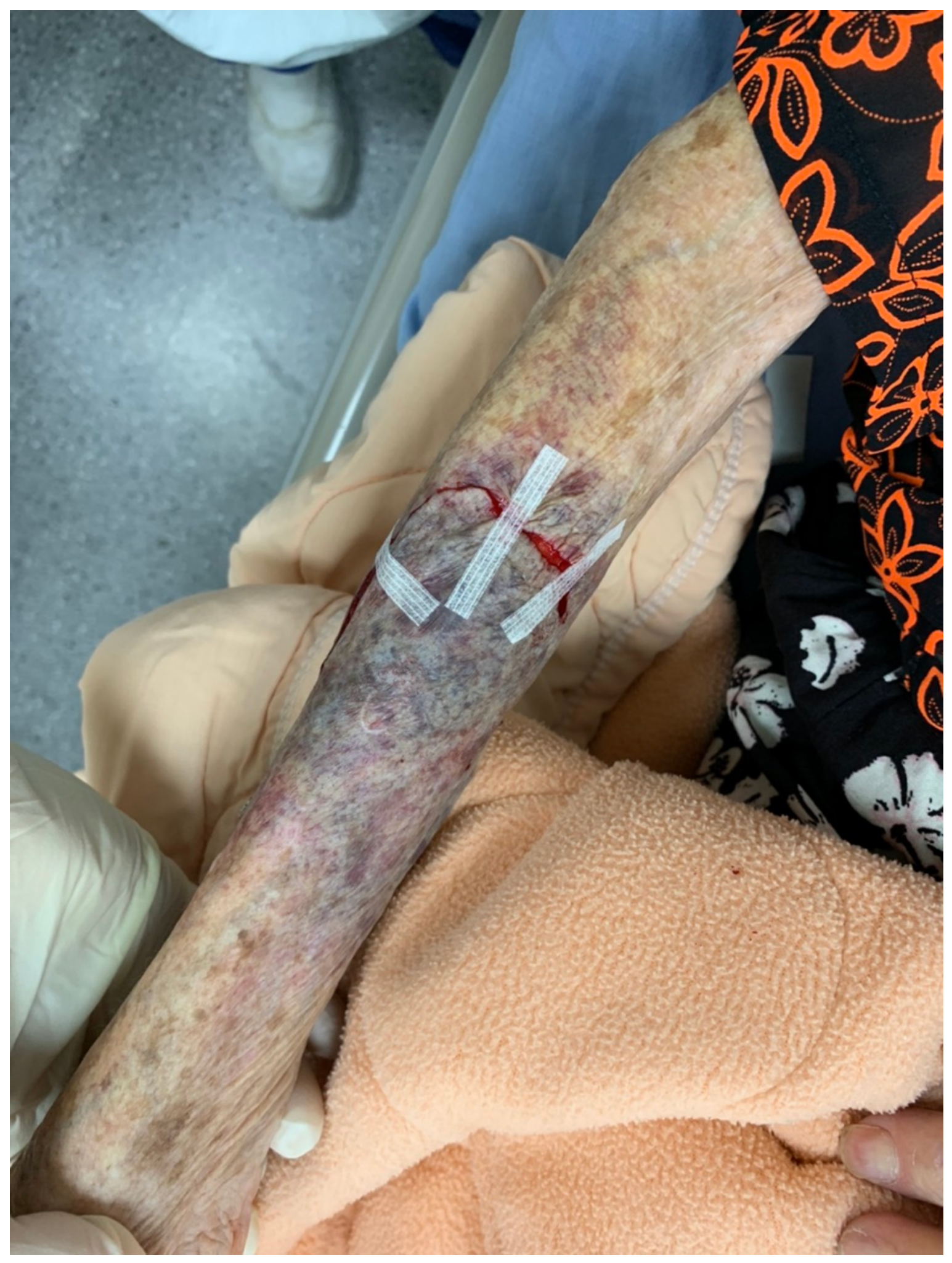

Figure 1

The skin tear was realigned as much as possible. Occasionally, remanent defect can be seen. 


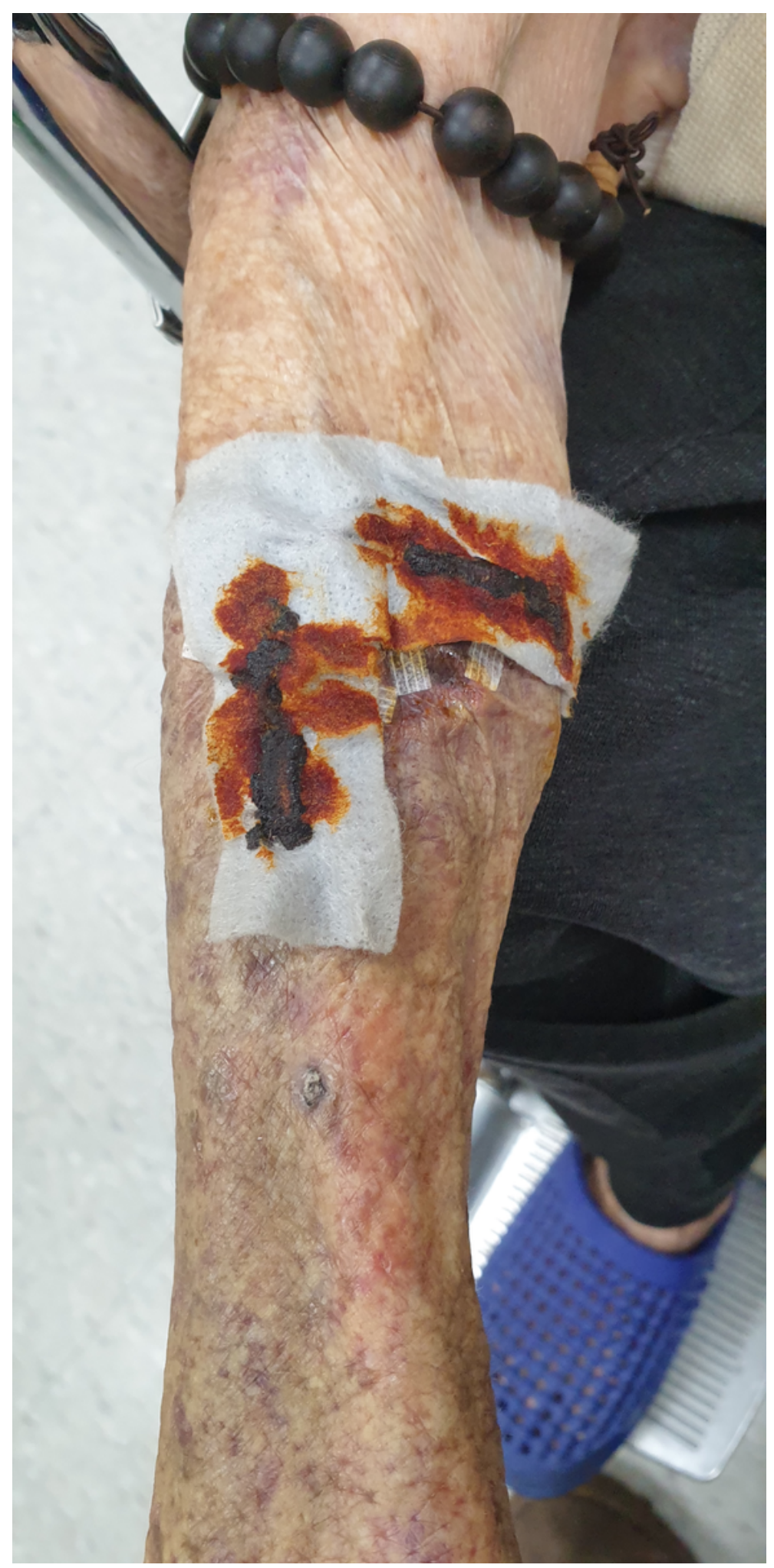

\section{Figure 2}

The silver-based hydrofiber dressing was examined at the outpatient clinic 3 days later to ensure that it was nice and dry. 


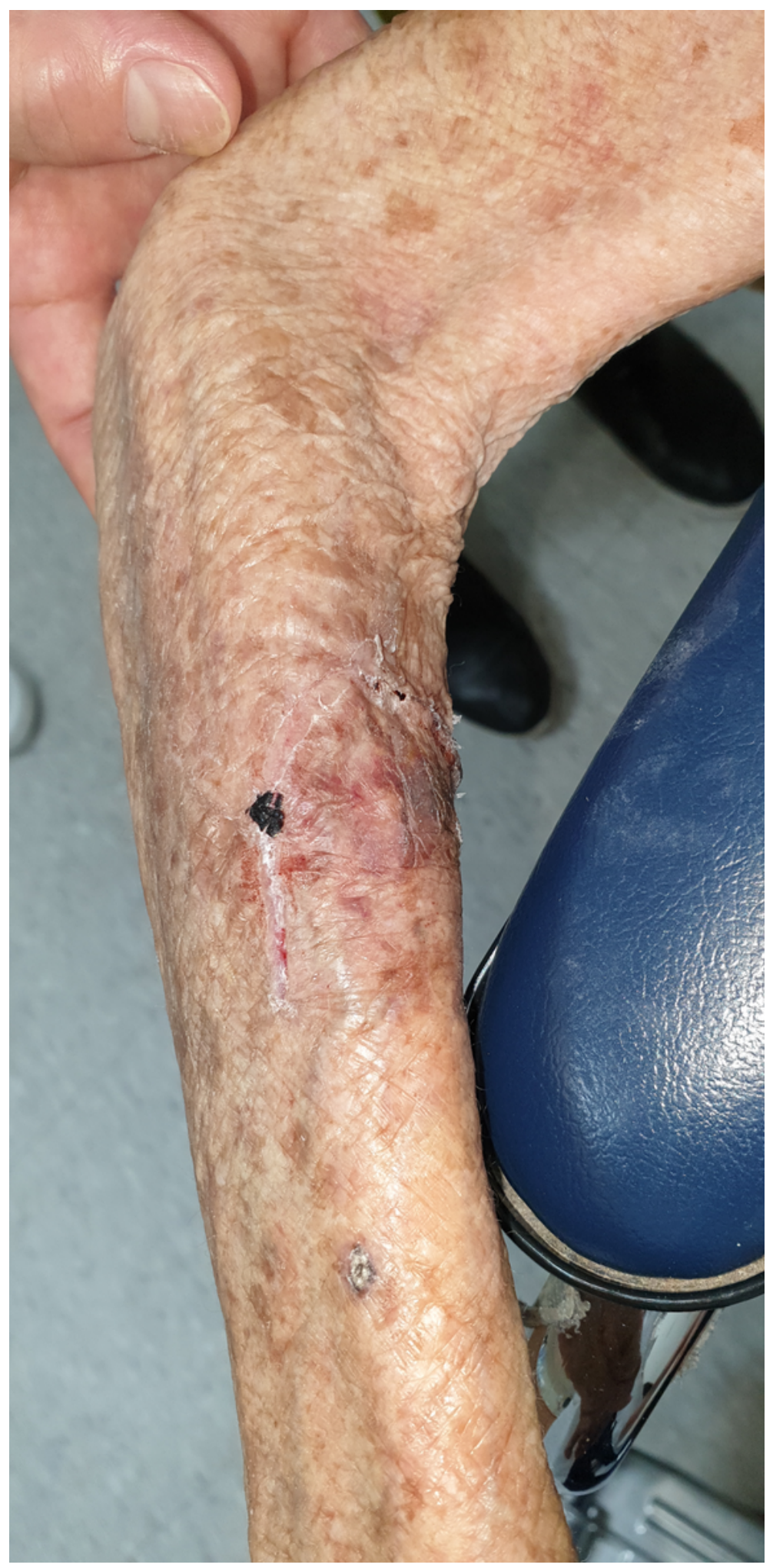

Figure 3

Removal of the silver-based hydrofiber dressing showing complete wound healing. 

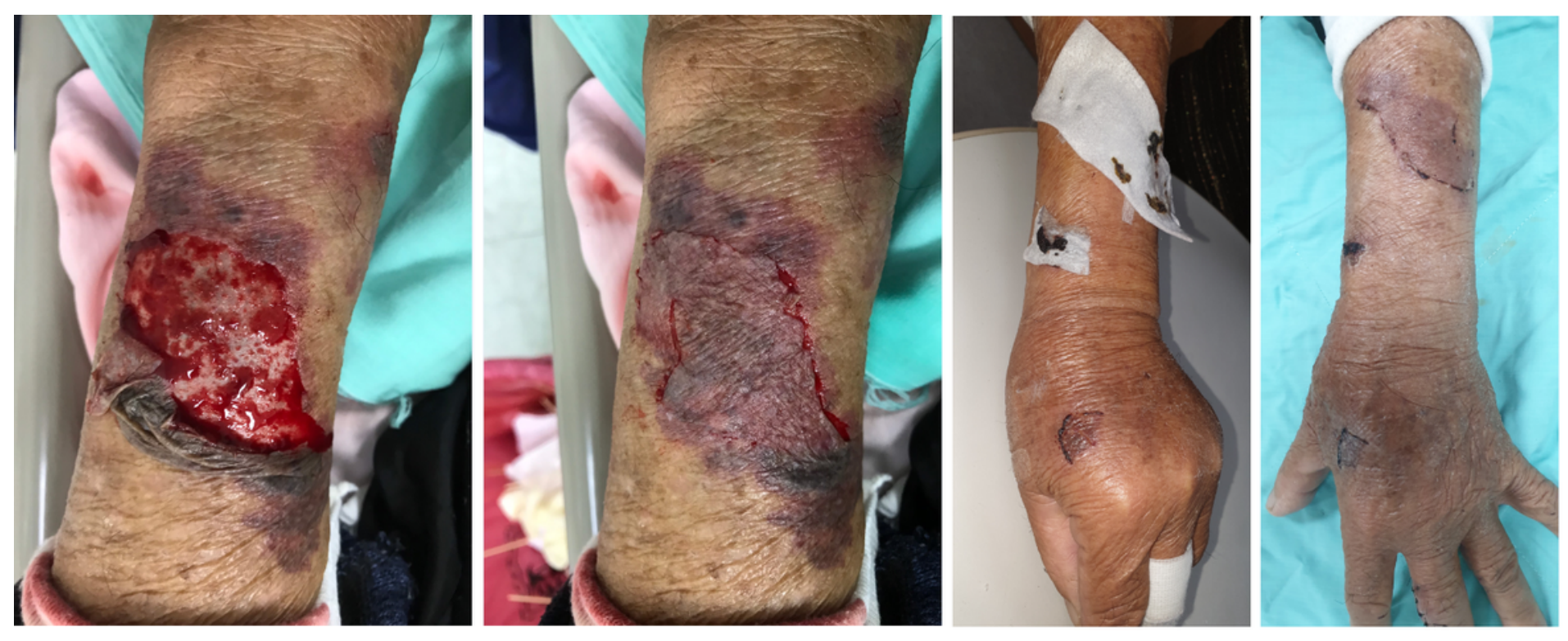

\section{Figure 4}

a-d: An 86 year old male with skin tear of the right forearm due to minor trauma when he fell from his chair. A class II skin tear was seen. The skin flap was replaced back, realigned and covered with a silverbased hydrofiber dressing. Review of the dressing 3 days later showed it to be nice and dry. The dressing was removed 17 days later and showed complete healing of the skin tear.
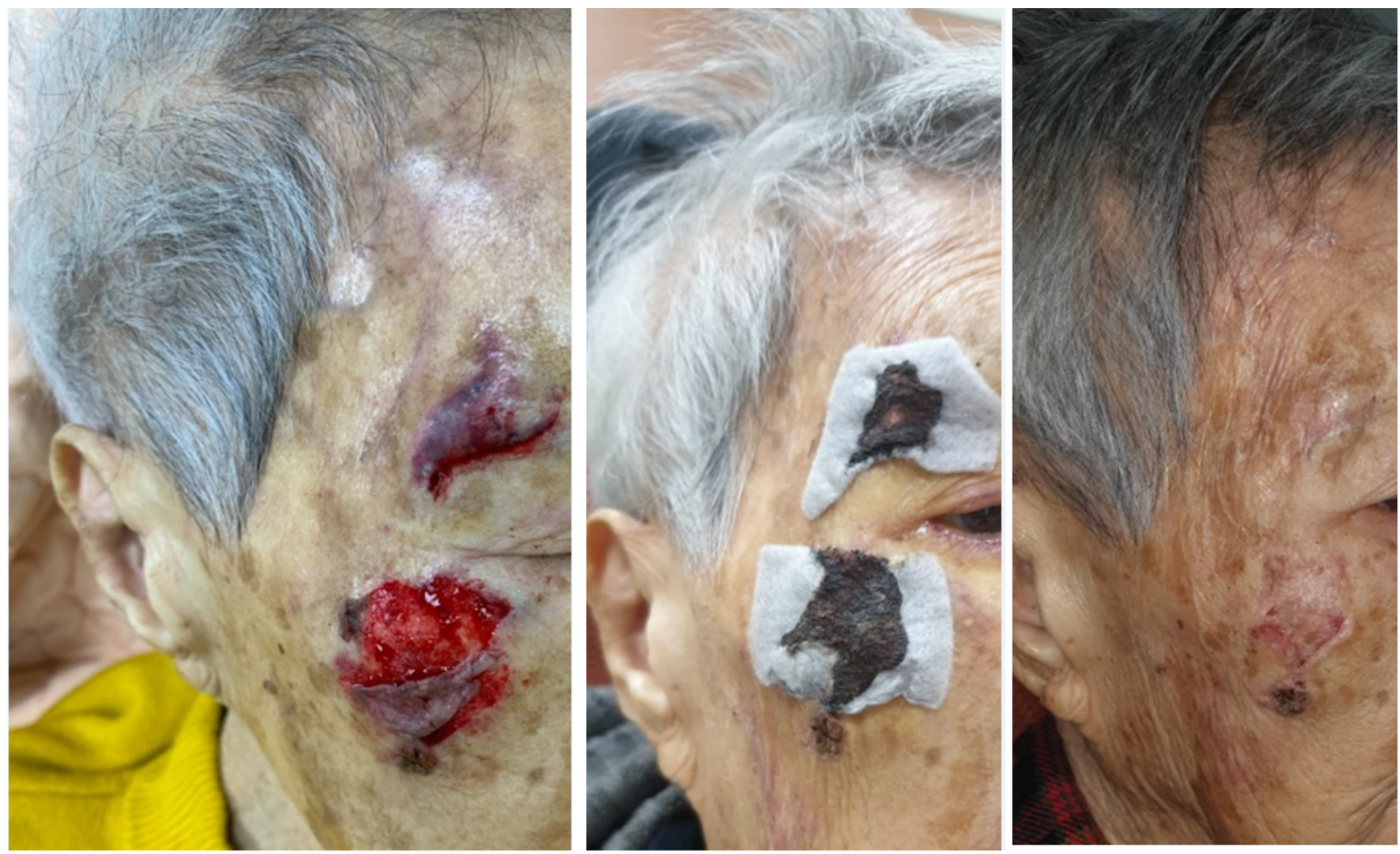


\section{Figure 5}

a-c: A 82 year old woman who fell and sustained class II skin tears to her right face. Silver-based hydrofiber dressing was used for wound coverage after the skin flap was realigned. The dressing was removed 10 days later and showed complete healing of her skin tear. 